\title{
Anterior Chest Wall Involvement in Spondyloarthritis Patients as Detected by Magnetic Resonance Imaging: A Case Series and Literature Review
}

\author{
Tae-Han Lee, M.D. ${ }^{1}$, Chul-min Lee, M.D. ${ }^{2}$, Tae-Hwan Kim, M.D., Ph.D. ${ }^{1}$, Seunghun Lee, M.D., Ph.D. ${ }^{2}$ \\ ${ }^{1}$ Department of Rheumatology, Hanyang University Hospital for Rheumatic Diseases, ${ }^{2}$ Department of Radiology, Hanyang University Seoul \\ Hospital, Seoul, Korea
}

\begin{abstract}
Magnetic resonance imaging (MRI) plays an important role in diagnosing and classifying axial spondyloarthritis (SpA) and is also useful for appropriate evaluation of disease status owing to its ability to detect inflammation early and reveal structural changes. However, dedicated MRI for the anterior chest wall (ACW) is not routinely considered despite relatively frequent presence of ACW lesions. To date, no study has investigated the imaging findings and clinical features of ACW involvement in Korean SpA patients. Thus, we aimed to show ACW involvement in SpA patients using ACW lesions found by MRI. We describe 20 cases of ACW involvement in which MRI-detected manubriosternal joint lesions. The lesion types included subchondral bone marrow edema, marginal or central bone erosions, subchondral fat infiltration or deposition, and ankylosis, with erosions being the most prevalent finding. We also provide the literature review results describing MRI findings of ACW lesions in SpA patients. (J Rheum Dis 2021;28:159-164)
\end{abstract}

Key Words. Anterior chest wall, Manubriosternal joint, Spondyloarthritis, Magnetic resonance imaging

\section{INTRODUCTION}

Inflammatory involvement of the anterior chest wall (ACW) is a well-known clinical feature of spondyloarthritis (SpA), possibly worsening the overall quality of life of these patients [1]. The ACW lesions might occur in the sternoclavicular joint (SCIJ), manubriosternal joint (MSJ), and costosternal joint (CSJ). Recent large sample-size studies reported ACW involvement, as identified by clinical examination, to be frequent, occurring in $26 \%$ $\sim 45 \%$ of the patients [2-4]. However, given the complexity of this anatomic region, clinical examinations alone might have limited ability to accurately assess the presence of such lesions [5]. In contrast, inflammation-like changes on the ACW, particularly in the MSJ, could also be observed in healthy individuals [6].

Magnetic resonance imaging (MRI) of the sacroiliac joint and spine is increasingly used to diagnose and classify axial SpA (axSpA). It is also used for evaluating treatment effectiveness owing to its ability to detect inflammation early and reveal structural changes [7]. However, validated or preferred imaging modalities to evaluate ACW involvement have not been established yet [8]. Indeed, evaluating the presence of ACW lesions tends to be overlooked in clinical practice, and imaging assessment for this region is not routinely considered.

To date, no study has investigated the imaging findings of ACW lesions and clinical characteristics of ACW involvement in Korean SpA patients. Thus, we describe a case series of ACW involvement in which spinal MRI-detected MSJ lesions in patients with ankylosing spondylitis (AS) and non-radiographic axSpA (nr-axSpA). Additionally, a review of the literature on such MRI findings was performed.

Received : December 31, 2020, Accepted : January 25, 2021

Corresponding to : Seunghun Lee (1D http://orcid.org/0000-0002-4348-7993

Department of Radiology, Hanyang University Seoul Hospital, 222-1, Wangsimni-ro, Seongdong-gu, Seoul 04763, Korea. E-mail : radsh@hanyang.ac.kr

Copyright (c) 2021 by The Korean College of Rheumatology.

This is an Open Access article, which permits unrestricted non-commerical use, distribution, and reproduction in any medium, provided the original work is properly cited. 
The Institutional Review Board of our university hospital approved this study (HYUH 2020-08-011-001), and the need for patient consent was waived by the Institutional Review Board because of the retrospective nature of our study.

\section{CASE REPORT}

We retrospectively reviewed the radiology database for reports of MRI-detected ACW lesions in patients with rheumatic diseases at our institution, covering the period between January 2015 and May 2020, and using the search term "manubriosternal." Most patients underwent spinal MRI, which offers sagittal but not coronal images of the ACW. This limits its ability to perform accurate imaging assessment of SClJ and CSJ. Thus, abnormal MRI findings in the ACW region focused on the MSJ.

Twenty patients (17 with AS and three with nr-axSpA) with abnormal findings of MSJ on MRI were included in this study. Demographic and clinical data of the patients are shown in Table 1. The patients had a median age of 37 years (range, $21 \sim 69$ years). Thirteen patients $(65.0 \%)$ were men. HLA-B27-positive was noted in $84.2 \%$ of the available data. The median symptom duration was 7.5 years ( $0.5 \sim 26.0$ years). Nine of the 20 patients had a history of ACW pain, and four had ACW pain at the time of MRI examination. ACW pain onset time was highly variable among the patients, ranging from five years before diagnosis to 18 years after disease diagnosis. One patient reported ACW pain as the initial symptom of the disease. The MRI findings of the MSJ lesions with their patterns and frequencies are as follows: joint erosion (65.0\%) was the most prevalent finding, followed by bone marrow edema (BME) (30.0\%), periarticular fat deposition (20.0\%), and joint ankylosis (15.0\%). Active inflammatory lesions and chronic structural damage were simultaneously observed in four patients. Figures 1 3 show examples of MRI-detected MSJ lesions. Sagittal MR images of BME, joint erosion, periarticular fat deposition, and ankylosis of the MSJ in patients with and without a history of ACW

Table 1. Demographic and clinical characteristics of patients with manubriosternal joint lesions identified by magnetic resonance imaging

\begin{tabular}{|c|c|c|c|c|c|c|c|c|c|}
\hline Case no. & $\begin{array}{c}\text { Sex/Age } \\
(y r)\end{array}$ & Diagnosis & $\begin{array}{l}\text { Duration* } \\
\text { (yr) }\end{array}$ & HLA-B27 & $\begin{array}{l}\text { History of } \\
\text { ACW pain }\end{array}$ & $\begin{array}{l}\text { Peripheral } \\
\text { enthesitis }^{\dagger}\end{array}$ & $\begin{array}{l}\text { Radiographic } \\
\text { sacroiliitis }^{\ddagger}\end{array}$ & $\mathrm{ESR}^{\S}$ & $\mathrm{CRP}^{\S}$ \\
\hline 1 & M/69 & AS & 12 & + & Y & Heel & Grade 2 & 11 & 0.3 \\
\hline 2 & $M / 32$ & AS & 3.5 & + & Y & $\mathrm{N}$ & Grade 3 & 53 & 3.9 \\
\hline 3 & $F / 68$ & AS & 4 & - & Y & $\mathrm{N}$ & Grade 3 & 67 & 1.5 \\
\hline 4 & $M / 31$ & AS & 6 & NA & Y & $\mathrm{N}$ & Grade 4 & 16 & 1.2 \\
\hline 5 & $F / 39$ & AS & 13 & + & Y & $\mathrm{N}$ & Grade 4 & 13 & 1.1 \\
\hline 6 & $\mathrm{~F} / 40$ & AS & 18 & + & Y & $\mathrm{N}$ & Grade 3 & 76 & 1.2 \\
\hline 7 & $\mathrm{M} / 24$ & AS & 11 & + & Y & $\mathrm{N}$ & Grade 2 & 2 & $<0.5$ \\
\hline 8 & $F / 21$ & AS & 6 & + & Y & $\mathrm{N}$ & Grade 3 & 35 & 0.9 \\
\hline 9 & $M / 22$ & AS & 8 & + & $\mathrm{N}$ & $\mathrm{N}$ & Grade 4 & 46 & 2.6 \\
\hline 10 & $F / 58$ & AS & 24 & + & $\mathrm{N}$ & $\mathrm{N}$ & Grade 3 & 43 & 0.36 \\
\hline 11 & $\mathrm{~F} / 52$ & AS & 11 & + & $\mathrm{N}$ & $\mathrm{N}$ & Grade 3 & 6 & NA \\
\hline 12 & M/35 & AS & 7 & + & $\mathrm{N}$ & Plantar & Grade 3 & $\mathrm{NA}$ & NA \\
\hline 13 & $M / 43$ & AS & 26 & + & $\mathrm{N}$ & $N$ & Grade 4 & 10 & $<0.5$ \\
\hline 14 & $\mathrm{~F} / 61$ & AS & 3.7 & - & $\mathrm{N}$ & Plantar & Grade 3 & NA & NA \\
\hline 15 & $M / 21$ & AS & 5 & + & $\mathrm{N}$ & Plantar & Grade 3 & 68 & 2.8 \\
\hline 16 & $M / 23$ & AS & 8 & + & $\mathrm{N}$ & $\mathrm{N}$ & Grade 2 & 66 & 1.9 \\
\hline 17 & M/55 & AS & 21 & + & $\mathrm{N}$ & $\mathrm{N}$ & Grade 4 & 30 & 1.0 \\
\hline 18 & M/33 & nr-axSpA & 5 & - & $\mathrm{Y}$ & $\mathrm{N}$ & Grade 0 & 21 & $<0.5$ \\
\hline 19 & $M / 53$ & nr-axSpA & 0.5 & + & $\mathrm{N}$ & $\mathrm{N}$ & Grade 0 & 49 & 1.6 \\
\hline 20 & $M / 25$ & nr-axSpA & 3 & + & $\mathrm{N}$ & $\mathrm{N}$ & Grade 0 & NA & NA \\
\hline
\end{tabular}

MRI: magnetic resonance imaging, HLA: human leukocyte antigen, ACW: anterior chest wall, ESR: erythrocyte sedimentation rate $(\mathrm{mm} / \mathrm{h})$, CRP: C-reactive protein $(\mathrm{mg} / \mathrm{dL}), \mathrm{AS}$ : ankylosing spondylitis, nr-axSpA: non-radiographic axial spondyloarthritis, NA: not available, M: male, F: female, N: no, Y: yes. *The period from the onset of initial disease manifestation to the time of inclusion in the study. ${ }^{\dagger}$ Refers to the cases where the patients have ever experienced peripheral enthesitis. ${ }^{\ddagger}$ The worst grade of the two sacroiliac joints is described. ${ }^{\S}$ Values at the time of MRI examination. 

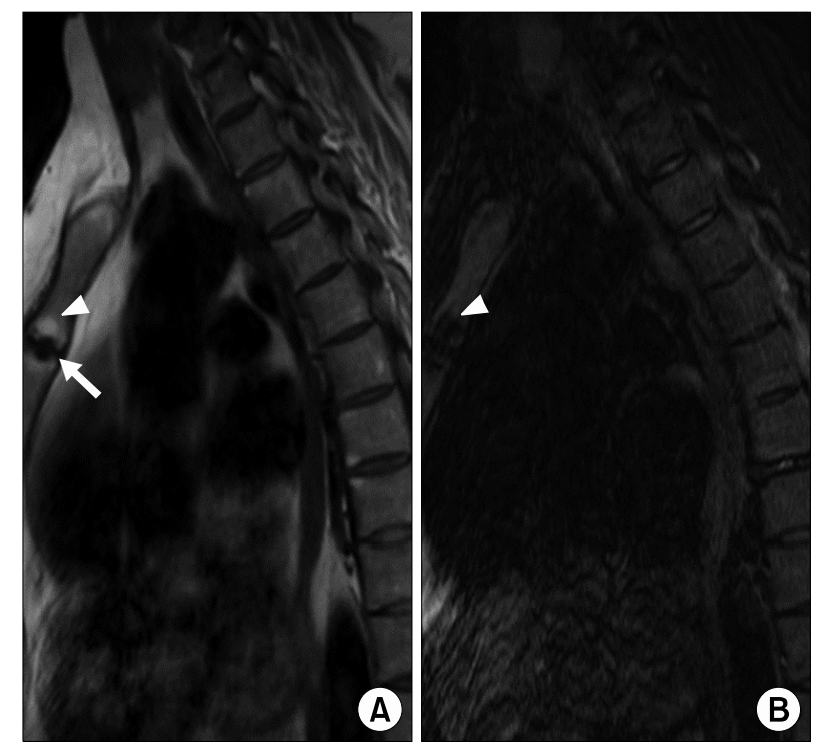

Figure 1. Sagittal MR images from Dixon sequence of a 40-year-old female AS patient. The patient underwent thoracic spine MRI because of ACW pain and worsening back pain during TNF inhibitor therapy. T1-weighted (A) and T2-weighted water-only (B) images of the ACW included in the field of view for thoracic spine MRI. The images show bony erosion (arrow) and periarticular fat deposition (arrowheads) at the MSJ. MRI: magnetic resonance imaging, AS: ankylosing spondylitis, TNF: tumor necrosis factor, ACW: anterior chest wall, MSJ: manubriosternal joint.

pain are presented.

\section{Literature review}

We searched PubMed and EMBASE from their inception until $26 \mathrm{July} 2020$. The terms used in MeSH and free-text searches were categorized into the following three concepts: "spondyloarthritis," "anterior chest wall," and "magnetic resonance imaging." The terms corresponding to each concept were searched individually and then integrated with the Boolean term "AND". Four studies were finally included in our review [2,9-11], with their details summarized in Table 2.

The ACW involvement in AS patients identified by MRI was first reported in the 1997 study, but MRI was performed in only three of the 50 subjects [9]. In 2012, Weber et al. [2] reported that MRI-detected ACW involvement was present in $72(59.0 \%)$ of 122 SpA patients, with MSJ being most frequently affected, followed by SCIJ and CSJ. In the MRI findings of the entire ACW region, including MSJ, SCIJ, and CSJ, BME was observed in $44.3 \%$ of the patients, erosion in $34.4 \%$, and fat infiltration in $27.0 \%$. Ankylosis of the MSJ was observed in
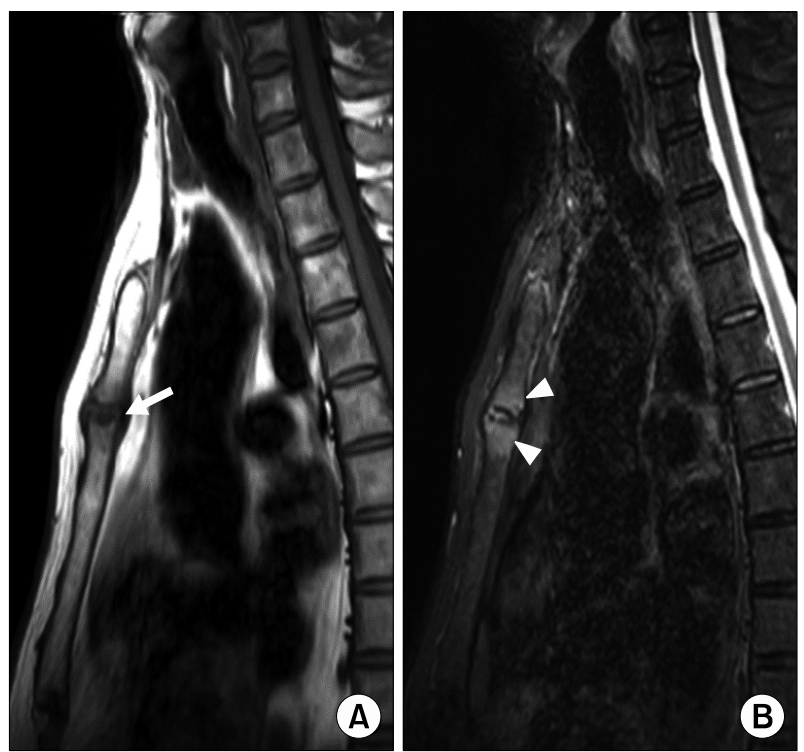

Figure 2. Sagittal MR images of a 53-year-old male patient with nr-axSpA, including T1-weighted (A) and T2-weighted STIR (B) images. Whole spine MRI was acquired following a clinical trial protocol in which the patient was enrolled. The patient did not experience ACW pain at the time of MRI. Bony erosion (arrow) and subchondral bone marrow edema (arrowheads) were observed at the MSJ. MRI: magnetic resonance imaging, nr-axSpA: non-radiographic axial spondyloarthritis, STIR: short tau inversion recovery, ACW: anterior chest wall, MSJ: manubriosternal joint.
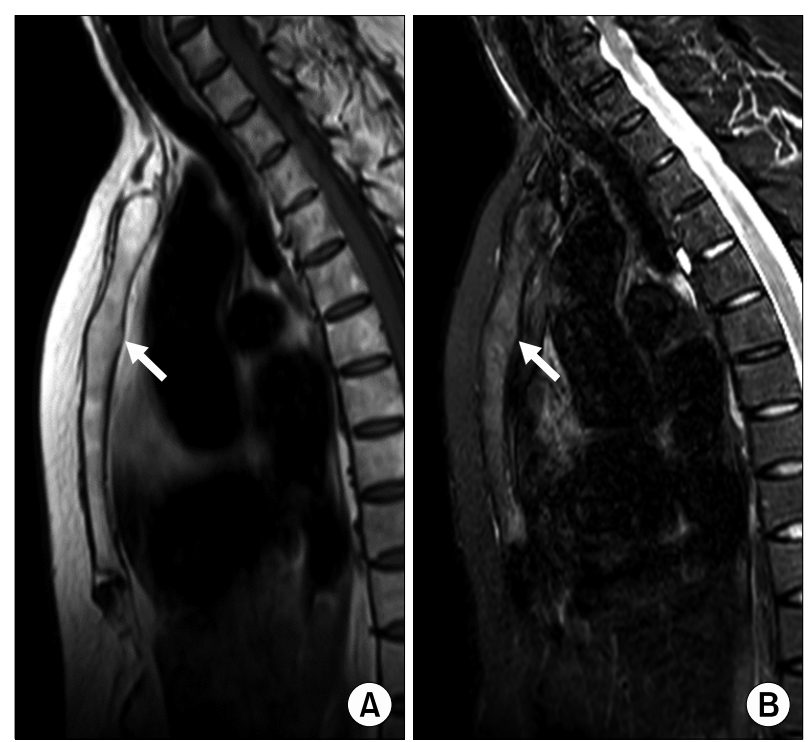

Figure 3. Sagittal T1-weighted (A) and T2-weighted STIR (B) images of a 52-year-old female AS patient, demonstrating ankylosis of the MSJ (arrows). The patient reported no ACW pain at the time of MRI. STIR: short tau inversion recovery, AS: ankylosing spondylotis, MSJ: manubriosternal joint, ACW: anterior chest wall, MRI: magnetic resonance imaging. 
Table 2. Summary of the systematic literature review

\begin{tabular}{|c|c|c|c|}
\hline Study & Study design and subjects & Imaging modality and outcome & Summary of findings related to our study \\
\hline $\begin{array}{l}\text { Fournie et al. } \\
\text { (1997) [9] }\end{array}$ & $\begin{array}{l}\text { - Prospective cross-sectional } \\
\text { - AS }(n=50), \operatorname{PsA}(n=50)\end{array}$ & $\begin{array}{l}\text { - } \mathrm{CT} \text {, bone scintigraphy, MRI* } \\
\text { - Frequency and distribution of } \\
\text { ACW lesions }\end{array}$ & $\begin{array}{l}\text { - MRI-positive was in two out of three } \\
\text { AS patients }\end{array}$ \\
\hline $\begin{array}{l}\text { Guglielmi et al. } \\
\text { (2009) [10] }\end{array}$ & $\begin{array}{l}\text { - Retrospective cross-sectional } \\
\text { - AS }(n=9), \text { PsA }(n=12) \\
\text { others }(n=9) \text { with SClJ swelling }\end{array}$ & $\begin{array}{l}\text { - X-ray, CT, MRI*, bone } \\
\text { scintigraphy } \\
\text { - Imaging findings of SCIJ }\end{array}$ & $\begin{array}{l}\text { - MRI findings of SClJ } \\
\text { - soft tissue swelling } 65 \%, \\
\text { intra-articular effusion } 53 \% \text {, synovial } \\
\text { reaction } 75 \%\end{array}$ \\
\hline $\begin{array}{l}\text { Weber et al. } \\
\text { (2012) [2] }\end{array}$ & $\begin{array}{l}\text { - Retrospective cross-sectional } \\
\text { - AS }(n=95), \text { nr-axSpA }(n=27) \\
\text { HS }(n=75)\end{array}$ & $\begin{array}{l}\text { - WB-MRI } \\
\text { - MRI findings of ACW and } \\
\text { agreement with clinical } \\
\text { assessment }\end{array}$ & $\begin{array}{l}\text { - } 59 \% \text { of the patients were positive on } \\
\text { MRI } \\
\text { - MSJ was the most frequently affected } \\
\text { joint, followed by SClJ and CSJ } \\
\text { - BME } 44.3 \% \text {, erosion } 34.4 \% \text {, fat } \\
\text { infiltration } 27.0 \% \text {, fusion (MSJ) } \\
11.5 \% \\
\text { - all types of MRI lesions were more } \\
\text { frequently observed in AS (65.3\%) } \\
\text { than nr-axSpA }(37.0 \%)\end{array}$ \\
\hline $\begin{array}{l}\text { Ramonda et al. } \\
\text { (2012) [11] }\end{array}$ & $\begin{array}{l}\text { - Prospective cross-sectional } \\
\text { - PsA }(n=24), \text { AS }(n=5), \text { uSpA } \\
(n=11) \text { with ACW symptoms } \\
\text { (early stage SpA patients) }\end{array}$ & $\begin{array}{l}\text { - MRI*, bone scintigraphy } \\
\text { - Agreement between MRI, } \\
\text { bone scan, and clinical } \\
\text { assessment }\end{array}$ & $\begin{array}{l}\text { - } 62.5 \% \text { of the patients were positive on } \\
\text { MRI and had ACW pain and/or } \\
\text { tenderness } \\
\text { - MRI signs } \\
\text { - active: bone edema and/or synovial } \\
\text { hyperemia } 27.5 \% \text {, swelling } 5 \% \\
\text { - advanced: erosion } 15 \% \text {, } \\
\text { osteoproductive process } 12.5 \% \text {, } \\
\text { osteophytes } 5 \%\end{array}$ \\
\hline
\end{tabular}

AS: ankylosing spondylitis, PsA: psoriatic arthritis, nr-axSpA: non-radiographic axial spondyloarthritis, HS: healthy subject, uSpA: undifferentiated spondyloarthritis, ACW: anterior chest wall, CT: computed tomography, MRI: magnetic resonance imaging, WB-MRI: whole-body magnetic resonance imaging, MSJ: manubriosternal joint, SCIJ: sternoclavicular joint, CSJ: costosternal joint, BME: bone marrow edema. *Performed to assess the ACW region.

$11.5 \%$ of patients. When comparing AS and nr-axSpA patients, all MRI lesion types were more frequently observed in AS patients. The ACW lesion distribution and the lesion type frequencies were shown to be similar in both groups.

Data of MRI findings from patients whose ACW involvement had already been confirmed by clinical assessment were available in two studies $[10,11]$. In a prospective cross-sectional study of 40 patients with early stage of the disease accompanied by ACW pain or tenderness noted on clinical examination, 25 (62.5\%) had abnormal MRI findings, showing active inflammation and advanced damage, while the remaining 15 patients (37.5\%) had normal MRI findings [11]. Similar results were found in the study by Guglielmi et al. [10], although the sample size was smaller.

\section{DISCUSSION}

Imaging assessment of the ACW region in SpA patients, in whom ACW involvement is known to be common, is relatively overshadowed by the diagnostic value of the sacroiliac joints imaging. However, the role of MRI in ACW evaluation, and its ability to detect acute inflammatory and chronic structural changes as in the sacroiliac joints, were confirmed through our literature review. We also found that the pattern and frequency of lesions detected by spinal MRI correspond with previous reports on BME, erosion, fat deposition, and ankylosis of the MSJ. To the best of our knowledge, this is the first description of MRI findings of inflammatory ACW involvement in Korean SpA patients.

The clinical involvement of the ACW has been reported in $35 \% \sim 50 \%$ of established SpA patients $[3,9]$. However, 
it also occurs in the early stage of the disease [11], and could be manifested as an initial disease symptom, ahead of inflammatory back pain. The ACW involvement could thus be interpreted as a diagnostic feature for SpA [4]. Similar to previous reports, ACW pain onset time was highly variable among our patients, including cases in which ACW pain occurred before the disease diagnosis and initial ACW pain symptoms appeared 18 years after the disease onset.

The prevalence of ACW involvement based on imaging assessment varies between imaging methods such as bone scintigraphy, computed tomography, ultrasonography (US), and MRI. It ranges from $35.5 \%$ to $67.2 \%$, with MSJ being the most commonly affected joint $[2,9,12,13]$. The detection variability between the imaging modalities might be attributable to the differences in their lesion detection sensitivity and specificity, in addition to study population heterogeneity. Among the imaging tools, MRI can reveal the type and severity of the lesions. Wholebody MRI, which allows visualization of the entire body, including structures of $\mathrm{ACW}$, is the primary modality used in recent studies [2,14]. Nevertheless, our cases show the usefulness of sagittal spinal MRI when assessing ACW involvement. Therefore, it would be helpful to include the ACW in the field of view when spinal MRI examination is planned, at least when dedicated MRI for the ACW is not routinely considered.

The lesion type frequencies in our patients were somewhat different from those identified in the literature review. Erosion was observed as the most frequent lesion type in our cases, while other studies reported BME to be the most common finding [2]. Because ACW involvement might be associated with disease duration and a higher disease activity $[12,13]$, the frequency of each lesion type would vary depending on the baseline characteristics of the patients.

Several studies found no correlation between MRI-detected ACW lesions and either the physician assessment or patient self-assessment [2,11,14,15]. More inflammatory lesions were found by MRI than through clinical examination in some studies [2], while other studies showed the opposite result $[11,15]$. Similarly, only about half of our patients reported having experienced or being currently accompanied by ACW pain. Weber et al. [2] suggested subclinical ACW inflammation as a possible explanation for the poor agreement between the two assessment methods. A recent study based on US findings, where $17.5 \%$ of patients had US abnormality without clinical symptoms, could further support the probability of subclinical joints and entheses inflammation in the ACW region [12]. Therefore, identifying the presence of ACW lesions which can be detected by spinal MRI would be helpful for more comprehensive assessment of disease extent.

\section{SUMMARY}

The spinal MRI findings in our case series showed acute inflammation and chronic structural damage of the ACW. These changes involved BME, erosions, fat deposition, and ankylosis, in line with lesions identified through a literature review. Further studies are needed to evaluate the diagnostic value of these findings and the association between MRI findings and clinical assessments.

\section{CONFLICT OF INTEREST}

No potential conflict of interest relevant to this article was reported.

\section{AUTHOR CONTRIBUTIONS}

T.H.K. and S.L. were involved in conception and design of study. T.H.L. and C.M.L. were involved in acquisition and analysis of data. All authors were involved in interpretation of the data, drafting the article, and revising it critically for important intellectual contents, and approving the final version of the article.

\section{REFERENCES}

1. Kiltz U, Braun J. Assessments of functioning in patients with axial spondyloarthritis. J Rheum Dis 2020;27:22-9.

2. Weber U, Lambert RG, Rufibach K, Maksymowych WP, Hodler J, Zejden A, et al. Anterior chest wall inflammation by whole-body magnetic resonance imaging in patients with spondyloarthritis: lack of association between clinical and imaging findings in a cross-sectional study. Arthritis Res Ther 2012;14:R3.

3. Elhai M, Paternotte S, Burki V, Durnez A, Fabreguet I, Koumakis E, et al. Clinical characteristics of anterior chest wall pain in spondyloarthritis: an analysis of 275 patients. Joint Bone Spine 2012;79:476-81.

4. Wendling D, Prati C, Demattei C, Loeuille D, Richette P, Dougados M. Anterior chest wall pain in recent inflammatory back pain suggestive of spondyloarthritis. data from the DESIR cohort. J Rheumatol 2013;40:1148-52.

5. Guglielmi G, Scalzo G, Cascavilla A, Salaffi F, Grassi W. Imaging of the seronegative anterior chest wall (ACW) syndromes. Clin Rheumatol 2008;27:815-21. 
6. Jurik AG, Zejden A, Lambert RG, Rufibach K, Hodler J, Maksymowych WP, et al. Pitfalls in MR morphology of the sterno-costo-clavicular region using whole-body MRI. Clin Radiol 2013;68:785-91.

7. Park EH, Yoon CH, Kang EH, Baek HJ. Utility of magnetic resonance imaging and positron emission tomography in rheumatic diseases. J Rheum Dis 2020;27:136-51.

8. Mandl P, Navarro-Compán V, Terslev L, Aegerter P, van der Heijde D, D'Agostino MA, et al.; European League Against Rheumatism (EULAR). EULAR recommendations for the use of imaging in the diagnosis and management of spondyloarthritis in clinical practice. Ann Rheum Dis 2015;74: 1327-39.

9. Fournié B, Boutes A, Dromer C, Sixou L, Le Guennec P, Granel J, et al. Prospective study of anterior chest wall involvement in ankylosing spondylitis and psoriatic arthritis. Rev Rhum Engl Ed 1997;64:22-5.

10. Guglielmi G, Cascavilla A, Scalzo G, Salaffi F, Grassi W. Imaging of sternocostoclavicular joint in spondyloarthropaties and other rheumatic conditions. Clin Exp Rheumatol 2009;27:402-8.

11. Ramonda R, Lorenzin M, Lo Nigro A, Vio S, Zucchetta P,
Frallonardo P, et al. Anterior chest wall involvement in early stages of spondyloarthritis: advanced diagnostic tools. J Rheumatol 2012;39:1844-9.

12. Verhoeven F, Guillot X, Godfrin-Valnet M, Prati C, Wendling D. Ultrasonographic evaluation of the anterior chest wall in spondyloarthritis: a prospective and controlled study. J Rheumatol 2015;42:87-92.

13. Verhoeven F, Sondag M, Chouk M, Prati C, Wendling D. Ultrasonographic involvement of the anterior chest wall in spondyloarthritis: factors associated with 5-years structural progression. A prospective study in 58 patients. Joint Bone Spine 2020;87:321-5.

14. Krabbe S, Eshed I, Sørensen IJ, Jensen B, Møller JM, Balding $\mathrm{L}$, et al. Whole-body magnetic resonance imaging inflammation in peripheral joints and entheses in axial spondyloarthritis: distribution and changes during adalimumab treatment. J Rheumatol 2020;47:50-8.

15. Althoff CE, Sieper J, Song IH, Weiß A, Diekhoff T, Haibel H, et al. Comparison of clinical examination versus whole-body magnetic resonance imaging of enthesitis in patients with early axial spondyloarthritis during 3 years of continuous etanercept treatment. J Rheumatol 2016;43:618-24. 